\title{
RESPONSE OF OREGON INLET TO PEA ISLAND BREACHING
}

\author{
Liliana Velasquez-Montoya ${ }^{1}$, Elizabeth J. Sciaudone ${ }^{1}$ and Margery F. Overton ${ }^{1}$
}

\begin{abstract}
This study aims to assess the effects of a new inlet on the hydrodynamics of a semi-permanent tidal inlet and the backbarrier sound. Research on dual-inlet interactions is motivated by the increased vulnerability of barrier islands to breaching during hurricanes, phenomenon that can have important consequences on the hydrodynamics and morphology of a barrier island system with pre-existing inlets. This particular study takes place in the northern Outer Banks of North Carolina, where Oregon Inlet is the main inlet connecting the Atlantic Ocean with the AlbemarlePamlico Sound. During Hurricane Irene in 2011, Pea Island - the island south of Oregon Inlet - was breached creating a new inlet that remained open until 2013. Dual-inlet interactions between Oregon Inlet and the new inlet in Pea Island are analyzed by means of numerical modeling experiments. Changes in flow velocities, water levels, and the tidal prism of Oregon Inlet due to the new inlet are computed for different wave and water level conditions. In addition to the actual inlet that opened in 2011, the effects of idealized inlets with different geometries and location are also included in this study. Results indicate that the original breach in Pea Island did not modify the dynamics of Oregon Inlet. Instead, its effects were restricted to a $5 \mathrm{~km}$ radius that extended mostly into the sound. The relative small size of the breach and its distance from Oregon Inlet are the two main factors that prevented dual-inlet interaction. Exploration of idealized breaching scenarios in Pea Island suggests that inlet spacing and breaching geometry play a major role in multiple inlet stability theory.
\end{abstract}

Keywords: Barrier Islands; Tidal Inlet; Outer Banks; Numerical Modeling; Dual-Inlet System; Inlet Stability

\section{INTRODUCTION}

The persistence of tidal inlets is fundamental for navigation, circulation of back barrier lagoons, water quality, fisheries, and flushing of wind-driven storm surges. Major barrier island systems in the world comprise multiple tidal inlets separated according to wave climate, tidal energy, and basin surface area (Hayes and FitzGerald 2013; Roos et al. 2013; Stutz and Pilkey 2011). The stability of multiple tidal inlet systems was initially studied by van de Kreeke (1990) under the assumption of spatially constant water elevation. This study concluded that in a two-inlet system there is not a set of equilibrium flow areas, meaning that one or both inlets will close. Friedrichs et al. (1993) tested the stability of a multiinlet system in Massachusetts after a new inlet had opened. Their results indicate that the flow through the new inlet reduces the surface gradient along the pre-existing inlets, which also reduces the velocity through the channels and causes instability.

Other studies indicate that multiple tidal inlet systems can persist over time. Van de Kreeke et al. (2008) state that the assumption of uniformly fluctuating water levels used in previous studies was restrictive and demonstrated the importance of topographic highs on the stability analysis of multiple inlet systems. Salles et al. (2005) argue that multiple tidal inlets can exhibit stable configurations and concluded that there is a strong hydrodynamic interaction between inlets. Pacheco et al. (2010) studied interconnected inlets and found that they can transfer portions of the tidal prism between them, while maintaining independent behavior for the majority of the spring tidal cycle. More recently, FarinhaFabiao et al. (2016) used a three-dimensional model and found that morphological changes in one inlet can have repercussions on tidal asymmetry in a different inlet. Still, further case studies are required to investigate how newly formed and transitory inlets could alter the dynamics of neighboring pre-existing stable inlets.

Studies of multi-inlet systems such as the aforementioned are particularly relevant for the Outer Banks of North Carolina, a barrier island system with five major semi-permanent inlets where island breaching is a recurrent phenomenon caused by combined action of sea level rise, storm surges, and vulnerable locations in the islands. Historically, the Outer Banks have experienced opening and closure of up to 30 inlets in the last 400 years (Fisher 1962) and the region between Oregon Inlet and Cape Hatteras has $62 \%$ of paleo-inlet geometries (Mallinson et al. 2010). The most recent opening of an inlet in the northern Outer Banks occurred in 2011 in Pea Island, $10 \mathrm{~km}$ south of Oregon Inlet (Figure 1). The new inlet evolved naturally and shoaled within two years of its opening (Velasquez et al. 2015). This event created the opportunity to study the effects of ephemeral inlets on semi-permanent inlets, a phenomenon that has remained relatively unexplored for real case scenarios.

This study aims to assess the effects of the breaching of Pea Island on the hydrodynamics of the back-barrier sound and Oregon Inlet, the only semi-permanent inlet in the northern Outer Banks. Changes

${ }^{1}$ Civil, Construction, and Environmental Engineering, North Carolina State University, Raleigh, NC, 27695, USA 
in flow velocities, water levels, and the tidal prism of Oregon Inlet caused by a new inlet are computed by means of numerical modeling experiments. The two-dimensional depth-averaged (2DH) hydrodynamic model used in this study is based on Delft3D and was previously validated for water levels and waves (Velasquez Montoya and Overton 2017). Analyses of Oregon Inlet are completed combined with (1) the actual breach that occurred in 2011, (2) idealized inlets at the same location of the breach with different geometries, and (3) other idealized inlet scenario at a vulnerable location on the island (red star in Figure 1c). Results presented here include the spatio-temporal variation of the hydrodynamics of Oregon Inlet and the back barrier bay due to the presence of a new inlet. Understanding the potential of ephemeral inlets to alter the hydrodynamics of their systems is essential for navigation, strategic management, successful post-storm recovery efforts, and infrastructure design on barrier islands.

\section{STUDY AREA}

Oregon Inlet is located at the north end of Pea Island in the Outer Banks of North Carolina (Figure 1). The inlet, which has remained over $600 \mathrm{~m}$ wide, connects the Albemarle-Pamlico Sound with the Atlantic Ocean through a main channel that reaches depths of up to $16 \mathrm{~m}$. Oregon Inlet has been open for over 170 years; before 1991 it used to be a migrating inlet until its south shoulder was stabilized with a terminal groin. The tidal prism of Oregon Inlet has been reported to be $113 \times 10^{6} \mathrm{~m}^{3}$ (Jarrett 1976). Measurements from Nichols and Pietrafesa (1997) indicate that the total volumetric flux of the inlet ranges from $120 \times 10^{6}$ to $500 \times 10^{6} \mathrm{~m}^{3}$ depending on inflow and outflow events. Given the persistence of the inlet and its natural geometric adjustments over time, it is believed that it has reached a stable equilibrium (Joyner et al. 1998).
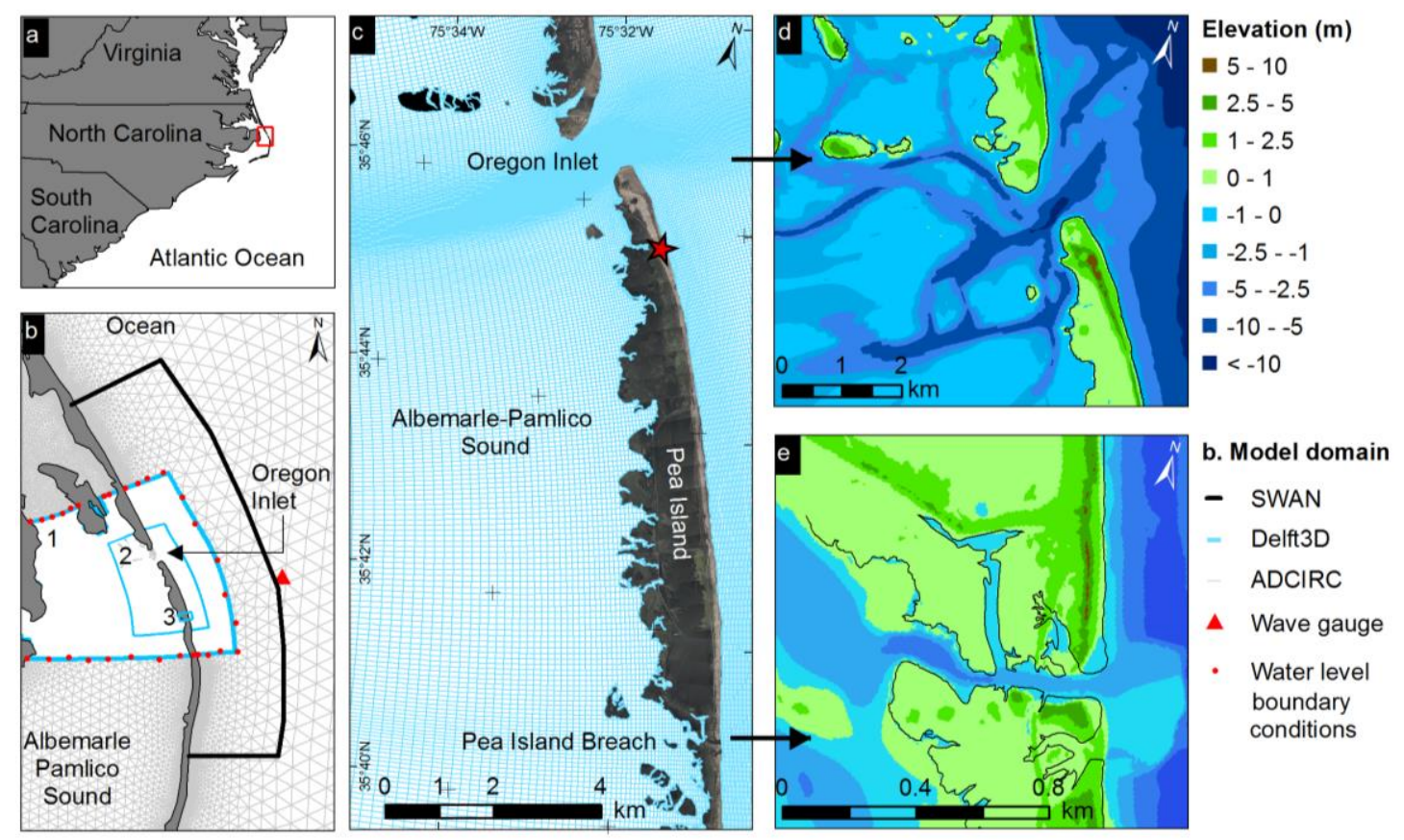

Figure 1. a) Location of study area, b) Model domains relative to the Outer Banks of North Carolina, c) Grid detail near Oregon Inlet and Pea island d) Bathymetry of Oregon Inlet, e) Bathymetry of Pea Island Breach.

Between Oregon Inlet to the north and Hatteras Island to the south is the Pea Island National Wildlife Refuge (PINWR). This $20.9 \mathrm{~km}$-long barrier island is reserved as a habitat for migratory birds and endangered species and to provide opportunities for public enjoyment of wildlife. Historical records indicate that Pea Island has had three inlets known as New Inlet, Loggerhead, and Chickinacommock (Fisher 1962). Pea Island remains undeveloped with the exception of the NC 12 highway that runs along the island. This highway constitutes the only road connecting the Outer Banks - including the towns on Hatteras Island - with mainland North Carolina. The road and the right-of-way are managed by the North Carolina Department of Transportation (NCDOT), while the rest of the land in Pea Island is managed by the U.S. Fish and Wildlife Service.

In August 2011 Pea Island was breached at two locations by a $1.9 \mathrm{~m}$ sound-side surge caused by Hurricane Irene. Both breaches occurred at narrow and low-lying portions of the island, where the dune 
field was degraded and paved surfaces funneled the water from the sound to the ocean (Kurum et al. 2012). One breach occurred in the south end of the PINWR and was artificially closed by NCDOT within days of its opening. The second breach was located in the middle of Pea Island $10 \mathrm{~km}$ south of Oregon Inlet. This inlet, known as Pea Island Breach, was allowed to evolve naturally. Pea Island Breach was as deep as $3.5 \mathrm{~m}$ and had minimum and maximum widths on the order of 30 and $70 \mathrm{~m}$, respectively. Pea Island Breach remained open for 2 years and its natural closure has been attributed to sediment infilling caused by seasonal storms (Safak et al. 2016; Velasquez-Montoya et al. 2018).

The Outer Banks of North Carolina have a semidiurnal and micro-tidal regime with a range of $1 \mathrm{~m}$ in the open coast and $0.30 \mathrm{~m}$ in the sound. The region has a seasonal wave climate with calm wave conditions from the south between May and August (summer), with significant wave heights (Hs) $<0.77$ $\mathrm{m}$ at $17 \mathrm{~m}$ depth. Storms with $\mathrm{Hs}>2 \mathrm{~m}$ are common between September and April (winter). Energetic wave conditions are generated by nor'easters and approach the study area from the northeast. Moreover, the region is prone to be hit by hurricanes between June and November. These extreme events can generate Hs above $6 \mathrm{~m}$ and storm surges from both the ocean and sound sides.

\section{NUMERICAL MODEL}

A 2DH model was built for Oregon Inlet and Pea Island Breach based on the Delft3D modeling platform (Lesser et al. 2004). Delft3D solves the Navier-Stokes equations for an incompressible fluid under the shallow water, Boussinesq, and hydrostatic pressure assumptions. The partial differential equations are solved in a discretized space using a finite difference scheme. Time integration is completed using the Alternating Direction Implicit method (Leendertse 1967). The hydrodynamic model is coupled online with the third generation phase-averaged wave model Simulating WAves Nearshore (SWAN) (Booij et al. 1999). Communication between Delft3D and SWAN occurs every 20 minutes; this online coupling between models allows accounting for the effects of waves on currents and vice versa.

Domain decomposition as defined in Deltares (2014a) was used to divide the computational domain into smaller subdomains that communicate with each other through shared internal boundaries. This approach allows coupling subdomains with enhanced resolution in areas of interest. It uses P-threading, resulting in more efficient computational times than a single-grid approach. To discretize the study area, a set of curvilinear grids was designed with increased resolution nearshore and within the inlets (Figure 1b-e). The black line in Figure $1 \mathrm{~b}$ indicates the limits of the SWAN grid extending $15 \mathrm{~km}$ offshore and $75 \mathrm{~km}$ alongshore with 18,213 elements. Blue lines in Figure 1b depict the spatial extent of the three hydrodynamic grids containing (1) the vicinity of Pea Island, (2) Oregon Inlet, and (3) Pea Island Breach, each one with 12,764, 34,056 and 46,080 elements, respectively. Element sizes reach $5 \mathrm{~m}$ in Pea Island Breach, $15 \mathrm{~m}$ in Oregon Inlet, $100 \mathrm{~m}$ alongshore, and $415 \mathrm{~m}$ offshore. To ensure stability in all grids, the computational time step was set to $12 \mathrm{~s}$.

The elevation of each node in the grids was assigned from interpolation of a composite of multiple topographic and bathymetric datasets with varying spatial and temporal resolution. Subaerial elevations were obtained from the 2014 NOAA NGS Topo-bathy Lidar and from digital elevation models (DEMs) of Pea Island generated by the NCDOT based on photogrammetry techniques. The bathymetry of Oregon Inlet was interpolated from the October 2014 U.S. Army Corps of Engineers survey of the inlet. The bathymetry of Pea Island Breach corresponds to a 2011 post-hurricane Irene survey by Geodynamics (2011). The ebb delta and nearshore bathymetry of the breach were interpolated from the resulting morphology modeled by Kurum (2013), who simulated the island breaching event using eXtreme Beach behavior model (XBeach) (Roelvink et al. 2009). The depth of the sound and the rest of the model domain was interpolated from the Flood Mapping Project DEM (Blanton et al. 2008).

Water levels are passed into the lateral and open ocean boundaries of the Delft3D model from tideonly simulations from the continental-scale ADvanced CIRCulation (ADCIRC) model (Luettich et al. 1992). Coupling of ADCIRC and Delft3D models happens offline (i.e. ADCIRC runs first and apart from Delft3D) at the locations shown in red dots in Figure 1b. Wave boundary conditions are obtained from the Oregon Inlet Waverider gauge shown as a red triangle in Figure 1b. For simplicity, Hs, direction, and peak period (Tp) are assumed to be spatially constant along the open ocean boundary of the SWAN model. Delft3D simulations begin with uniform water levels followed by a 15-day tide-only spin-up period. Then, waves are forced in the simulations and the online coupling of Delft3D and SWAN begins.

Calibration and validation of the hydrodynamic model was completed by comparing simulated water levels and waves with observations at nearby gauges. The calibration consisted of varying the bed roughness coefficient and the horizontal eddy viscosity until the best match between simulations and observations was attained. Details of the model evaluation can be found in Velasquez-Montoya and 
Overton (2017) and are not repeated here. The final values of the parameters defined through the calibration processes are Chezy coefficient $=65$ and horizontal eddy viscosity $=1 \mathrm{~m}^{2} / \mathrm{s}$.

\section{NUMERICAL SIMULATIONS OF DUAL-INLET SCENARIOS}

The hydrodynamic effects of a new inlet across Pea Island are assessed through simulations under summer (calm), winter (energetic), and storm conditions. An initial set of simulations were completed with Oregon Inlet only and are used as the base simulations for comparison with different sets of simulations including a new inlet across Pea Island. The second set of simulations include both Oregon Inlet and the breach with its original geometry (Figure 2 scenario A).

The third and fourth sets of simulations include Oregon Inlet along with new inlets at the location of the breach, but each with a larger cross-sectional area than the original breach (Figure 2 scenarios B and C). These scenarios intend to illustrate the consequences of a larger inlet located in a known breachprone region, where larger inlets have existed in the past (Birkemeier et al. 1984). The idealized inlets in scenarios $B$ and $C$ have trapezoidal shapes with maximum depths of $3 \mathrm{~m}$ and widths ranging from 200 $\mathrm{m}$ to $400 \mathrm{~m}$. Typical cross-sectional profiles of the breach for scenarios A, B, and C are shown in the right column in Figure 2, such profiles correspond to cross-sectional areas of $100 \mathrm{~m}^{2}, 650 \mathrm{~m}^{2}$, and 1314 $\mathrm{m}^{2}$ (below the zero elevation contour), respectively.
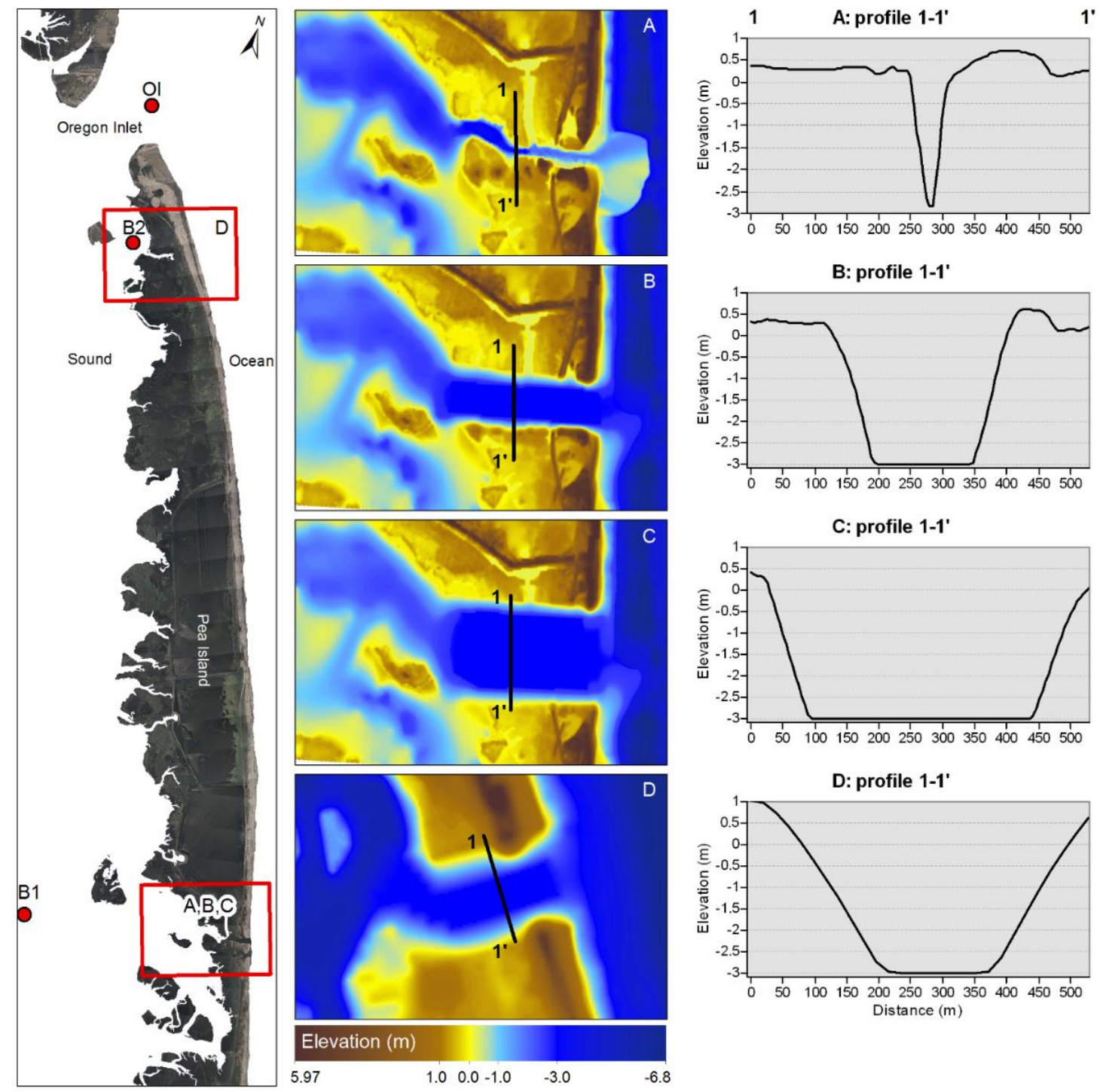

Figure 2. Pea Island Breach scenarios. Left: location of breaches and control points, center: bathymetry of breaching scenarios, right: inlet profiles at transects 1-1' defined in the center panels. Elevations relative to NAVD88. 
An additional set of simulations includes Oregon Inlet and an artificial inlet $1.5 \mathrm{~km}$ to the south (red star in Figure 1c). This idealized new inlet is located in an area known as the "Canal Zone", which has been reported vulnerable to storms in previous studies (Overton and Fisher 2004; Sciaudone et al. 2016). The vulnerability of this region has been explained by the transitory nature of its dunes that continuously lose height due to aeolian sediment transport and overwash. Furthermore, an estuarine channel extending $350 \mathrm{~m}$ into the island (Figure 2 left, panel D) increases the chances of directing storm surge toward this specific spot, which is only $360 \mathrm{~m}$ wide. The idealized inlet has a trapezoidal shape with a cross-sectional area of $920 \mathrm{~m}^{2}$, an intermediate area compared to the breaches in scenarios B and C.

Figure 3 shows the wave boundary conditions representing summer, winter, and a hurricane. The latter is based on the waves measured at Oregon Inlet Waverider during Hurricane Arthur (July 2014). Comparisons between the base simulation (Oregon Inlet only) and the dual inlet scenarios are performed for the three climatic conditions by subtracting flow velocities at each node in the model domain. The regions where changes in velocities exceed $0.05 \mathrm{~m} / \mathrm{s}$ are considered influenced by the breach and are delineated. This method allows identifying the spatial extent where a breach modifies the hydrodynamics of the system. Altough the simulation period is one month for the summer and winter simulations and five days for the hurricane, the results of the simulations are spatially compared during ebb and flood phases of the spring tide, when higher velocities are expected to occur. The hurricane scenario is analyzed at the peak of the storm.

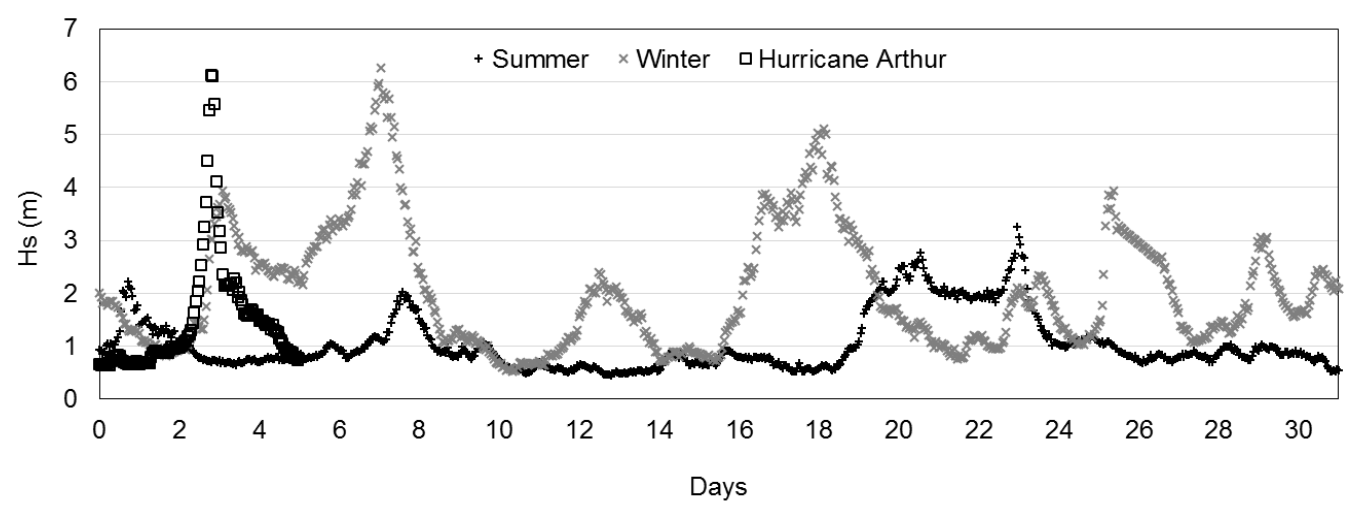

Figure 3. Wave boundary conditions for summer, winter and Hurricane Arthur

Changes in the water levels at Oregon Inlet and in the sound near the location of the new inlets (red dots named OI, B1, and B2 in left panel of Figure 2) are reviewed for the full length of the simulation. The tidal prism of Oregon Inlet and its changes due to the presence of new inlets across Pea Island are computed from simulated instantaneous discharge (Q) across the center of the inlet. As computed in the model, the instantaneous discharges retain additional volumetric contributions from the sound and the ocean. Thus, the tidal prism computed in this study represents the total volumetric flux across the inlet. Here the tidal prism $(\mathrm{P})$ is computed using Eq. 1 where $T_{E}$ is the ebb period, which is approximately 6 hours for Oregon Inlet.

$$
P=\int_{0}^{T_{E}} Q(t) d t
$$

\section{RESULTS}

\section{Spatiotemporal Changes in Flow Velocities Caused by New Inlets}

Areas where the new inlets cause changes in the currents larger than $0.05 \mathrm{~m} / \mathrm{s}$ under summer, winter and hurricane conditions are shown in Figure 4. In scenario A when Oregon Inlet and the original breach are simulated, the effects of the new inlet are localized in its vicinity extending $5 \mathrm{~km}$ into the sound during hurricane conditions and about $4 \mathrm{~km}$ under summer conditions (top left panel in Figure 4). Results from this scenario indicate that the original breach that opened during Hurricane Irene did not have any effects on the flow velocities at Oregon Inlet. However, it did modify the local water velocities in the sound and the ocean within a $5 \mathrm{~km}$ radius.

Idealized inlets with larger cross-sectional areas than the original breach (scenarios B and C in Figure 4) display an increase in the spatial extent where they modify the hydrodynamics of the system. Compared to the original breach (scenario A), scenarios B and C have areas of influence nearly 9, 5 and 3 times larger during summer, winter and hurricane conditions, respectively. Results from scenarios C 
and $\mathrm{B}$ are similar, but the new inlet in scenario $\mathrm{C}$ has a larger extent of influence than that in scenario $\mathrm{B}$ because the cross-sectional area of the former is about two times larger than the latter. Despite the increase in the area of influence for scenarios B and C, results indicate that changes in the circulation at Oregon Inlet were minimum and localized at both sides of the main channel of the inlet.
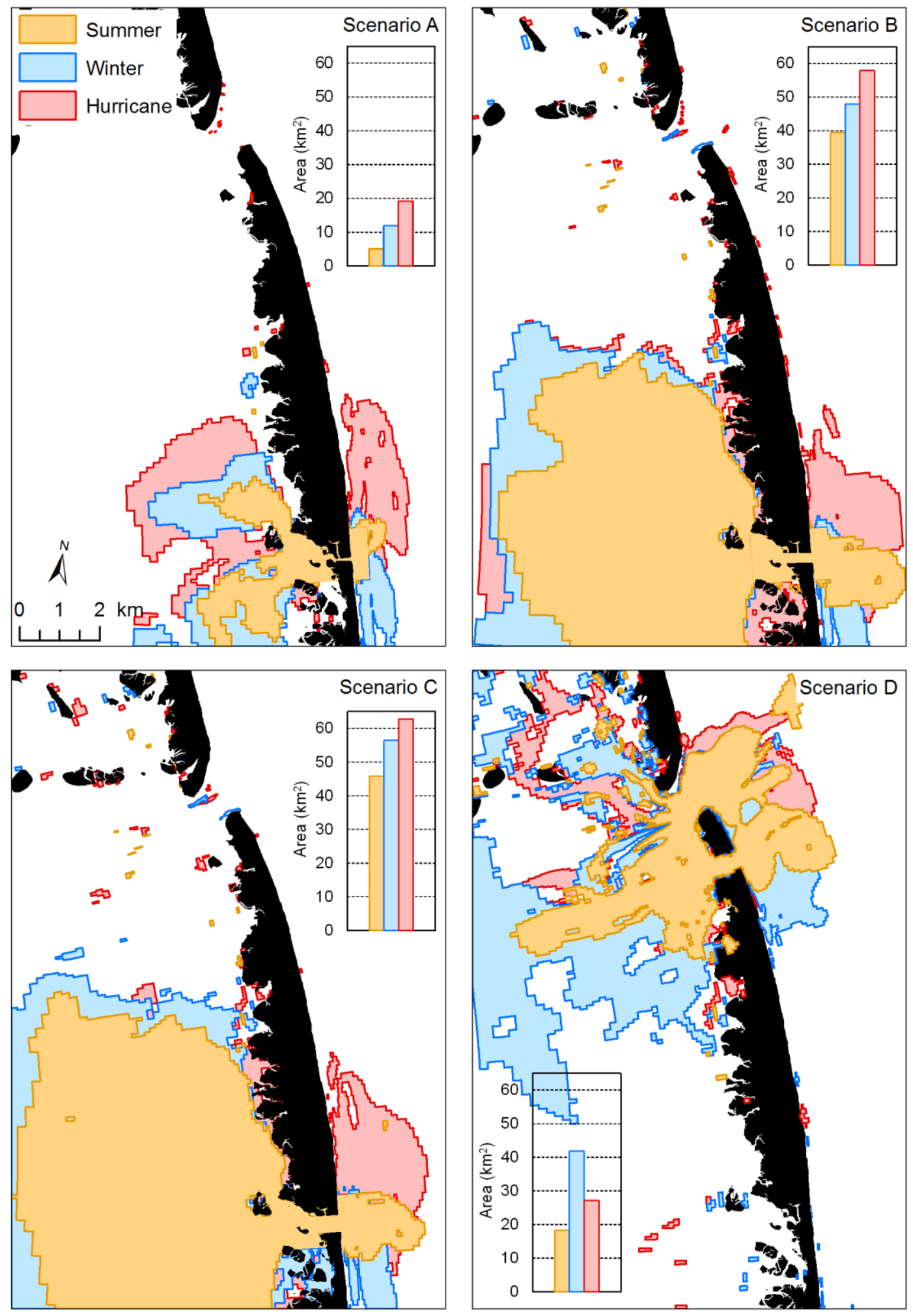

Figure 4. Spatial extent of the hydrodynamic effects of a new inlet in Pea Island. 
The bottom right panel in Figure 4 shows a very different behavior than previous scenarios. With an idealized inlet only $1.5 \mathrm{~km}$ away from Oregon Inlet, the latter experiences severe changes in velocities that extend from the main channel into the ebb and flood deltas, indicating a strong interaction between the two inlets. In scenario D, the spatial extent of the effects of the new inlet during winter exceed that of the hurricane conditions. Such behavior can be explained by the directionality of the waves and greater difference in velocities at the two inlets during the hurricane compared to smaller differences distributed in a larger area during the winter. In scenario D, flow velocities at Oregon Inlet are reduced by approximately $0.1 \mathrm{~m} / \mathrm{s}, 0.2 \mathrm{~m} / \mathrm{s}$ and $0.25 \mathrm{~m} / \mathrm{s}$ for summer, winter and hurricane conditions due to the new inlet.

The spatial extent where new inlets modify flow velocities in the sound and ocean shows a strong dependence on the wave boundary conditions. For all the scenarios, the areas that experienced significant changes in velocities are larger for hurricane and winter conditions than for summer conditions. Overall, new inlets tend to modify the currents in the sound on larger spatial scales than on the ocean side. Scenario D was the only test case that proved interaction between inlets; results suggest that the proximity of the idealized inlet to Oregon Inlet is the main factor generating this dual-inlet interaction.

\section{Effects of new inlets on the water levels at Oregon Inlet and the back barrier}

Comparison of modeled water levels from the base simulation (Oregon Inlet only) and scenarios A, B, C, and D were completed at station OI located in the main channel of Oregon Inlet. Scenarios A, B and $\mathrm{C}$ did not generate changes in water levels at this monitoring station. Scenario D caused minor changes in the range of water levels (Figure 5). Under summer (winter) conditions, the range of water levels increased by $0.02 \mathrm{~m}(0.03 \mathrm{~m})$ at OI. For the hurricane conditions, the increase in the peak water level was less than $0.02 \mathrm{~m}$. The small changes in water level ranges that occurred in scenario D are a consequence of local changes in the hydrodynamics due to the proximity of both inlets.

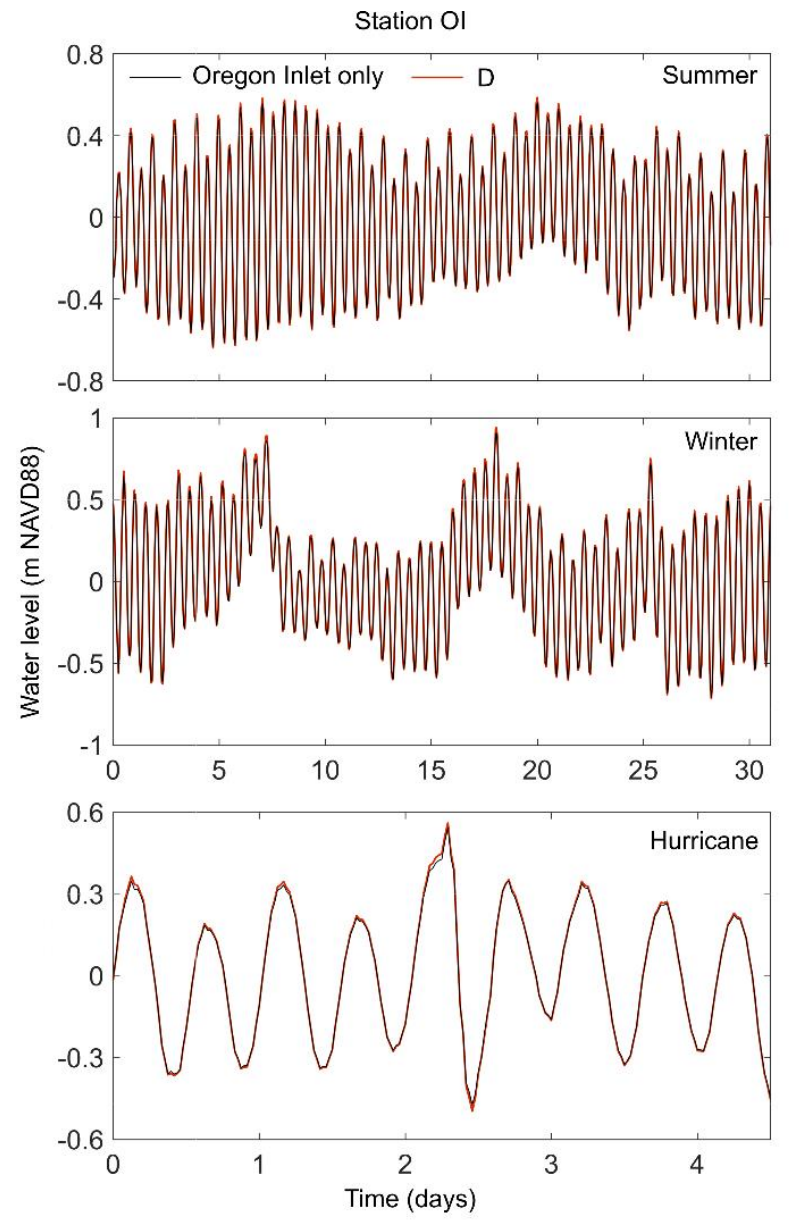

Figure 5. Comparison of water levels from the base simulation and scenario $D$ at station $O$. 
Scenario D generates changes in velocities at Oregon Inlet that exceed those in the base simulation by $30 \%$, being significantly higher difference than changes in water levels, which do not exceed a $3 \%$ diference. On the other hand, the scenarios with an inlet at the location of the original breach (A, B, and C) did not significantly modify the hydrodynamics at Oregon Inlet; instead, the effects of the new inlets are restricted to areas within their vicinity. This statement is true for both currents and water levels.

The effects of new inlets on the water levels in the back barrier were assessed by comparing the results of the base simulation with those from scenarios A, B, and C at station B1 (left panel Figure 6).Water levels from the base simulation and scenario A did not significantly differ at this specific location. For the summer, winter, and hurricane conditions tested, discrepancies in water levels between these two simulations were always below $0.01 \mathrm{~m}$.

Changes in water levels with respect to the base simulation begin to be noticeable in scenarios B and C. As expected, water level ranges increased with the size of the new inlet, with the bigger changes occurring in scenario $\mathrm{C}$ (green line in Figure 6) under winter conditions. Differences in water levels of up to $0.2 \mathrm{~m}$ between scenario $\mathrm{C}$ and the base simulation indicate a strong effect of the larger new inlet on the back barrier of Pea Island. Under hurricane conditions, the peak storm surge in the back barrier was $0.05 \mathrm{~m}$ higher in the base simulation than in scenario $\mathrm{C}$. A lower sound-side storm surge in scenario $\mathrm{C}$ is a consequence of having a new inlet draining the surge flowing from the sound to the ocean.
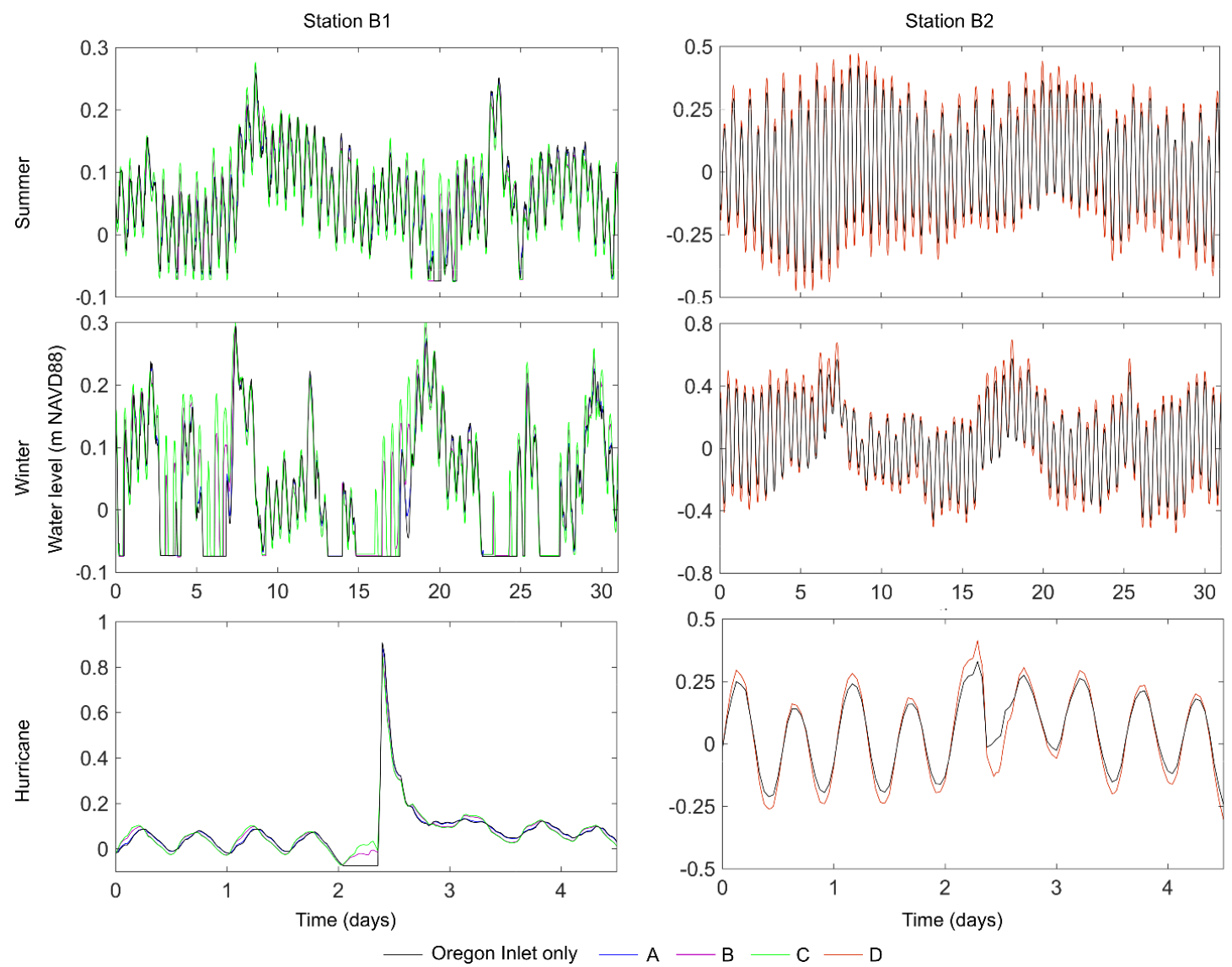

Figure 6. Comparison of water levels from the base simulation and scenarios A, B and C at station B1 and scenario D at station B2.

The right column of Figure 6 shows the water levels of the base simulation in black and those of scenario D in red at station B2. Under summer, winter, and hurricane conditions, the range of water levels at B2 was $0.1 \mathrm{~m}$ larger with the presence of the new inlet than with Oregon Inlet only. The increase in water level range at this location results from the additional volume of water entering the sound through the new inlet and passing across this location at each tidal cycle.

\section{Effects of new inlets on the discharge and tidal prism of Oregon Inlet}

According to the base simulation, the average tidal prism computed as the total volumetric flux of Oregon Inlet is $200 \times 10^{6} \mathrm{~m}^{3}$, with a minimum of $86 \times 10^{6} \mathrm{~m}^{3}$ and a maximum of $220 \times 10^{6} \mathrm{~m}^{3}$. These 
values fall within the volumetric fluxes reported by Nichols and Pietrafesa (1997). The tidal prism across the original breach in scenario A is $4 \times 10^{6} \mathrm{~m}^{3}$, which represents only $2 \%$ of the tidal prism of Oregon Inlet. As suggested from this and previous results, the relatively small size and prism of the breach and its distance to Oregon inlet prevented any significant interaction between the breach and the larger semipermanent inlet.

The prisms of the breaches in scenarios B and C are $24 \times 10^{6} \mathrm{~m}^{3}$ and $30 \times 10^{6} \mathrm{~m}^{3}$, respectively, reaching up to $15 \%$ of the prism of Oregon Inlet. Despite the increase in the volumetric capacity of the idealized inlets in these two scenarios, they did not significantly alter the discharge or the prism of Oregon Inlet. This result strengthens the findings from previous sections regarding the localized effect of the new breaches that did not reach the area of influence of Oregon Inlet.

Similar to scenario C, the average prism of the idealized inlet in scenario D is $32 \times 10^{6} \mathrm{~m}^{3}$. However, this time the prism of Oregon Inlet is reduced $8 \times 10^{6} \mathrm{~m}^{3}(4 \%)$ by the presence of the idealized inlet. The analysis indicates that the only breach that effectively modifies the dynamics of Oregon Inlet is the one in scenario D, suggesting that inlet spacing could be a dominant factor for dual-inlet interactions. Figure 7 shows the temporal variations in instantaneous discharge of Oregon Inlet for the base simulation (black lines) and scenario D (red lines) for summer, winter and hurricane conditions. Comparison with other scenarios is not presented because they don't modify the discharge across Oregon Inlet. Overall, under calm conditions, the instantaneous discharge of Oregon Inlet remains within $5,000 \mathrm{~m}^{3} / \mathrm{s}$. High energy events like winter storms and hurricanes increase the discharge across the inlet by up to $10,000 \mathrm{~m}^{3} / \mathrm{s}$.

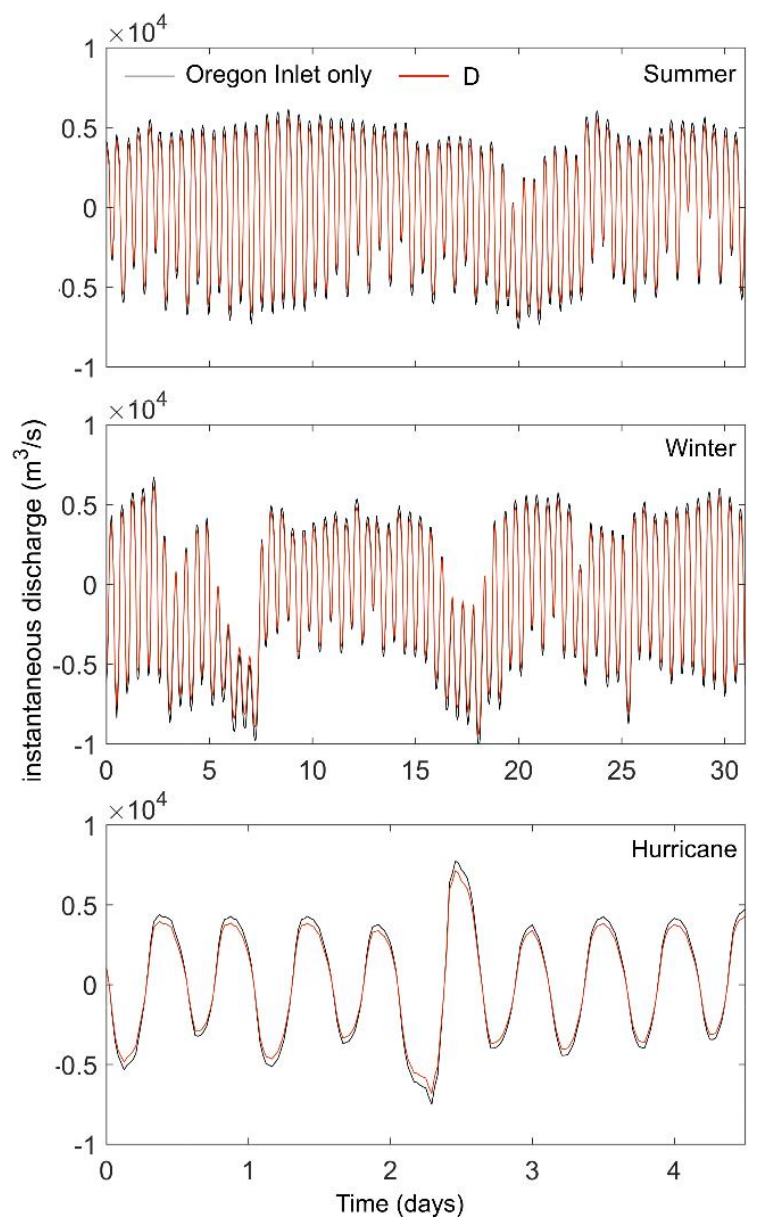

Figure 7. Comparison of instantaneous discharge from the base simulation and scenario $D$ at a cross-section in the center of Oregon Inlet

\section{DISCUSSION AND CONCLUSIONS}

Numerical modeling experiments allowed assessment of the effects that a new inlet in Pea Island could have on the hydrodynamics of the sound and Oregon Inlet. Changes in flow velocities, water levels, and the tidal prism of Oregon Inlet caused by four different inlets were quantified. It was found that the original Pea Island Breach that opened in 2011 did not modify the dynamics of Oregon Inlet. Instead, its 
effects were restricted to a $5 \mathrm{~km}$ radius that extended mostly into the sound. The relative small size of the breach and its distance from Oregon Inlet are the two main factors that prevented dual-inlet interaction. The large flow-conveyance capacity of Oregon Inlet makes it the dominant inlet in the northern Outer Banks.

Three additional scenarios with idealized inlets were used to identify the spatial extent over which new and larger inlets could modify the dynamics of Oregon Inlet and the sound. Increasing the size of the inlets at the original location of the breach enlarged their areas of influence in the sound, but their effects in Oregon Inlet were still negligible. Scenario D, with a new inlet located only $1.5 \mathrm{~km}$ south of Oregon Inlet was the only one that caused changes in the velocities, water levels, and tidal prism of Oregon Inlet. The cross-sectional area of the idealized inlet in this last scenario was within the areas of the channels in scenario $\mathrm{B}$ and $\mathrm{C}$, but the inlet spacing was reduced $85 \%$. This finding suggest that inlet spacing plays a major role in multiple inlet stability theory and it is consistent with the work of Roos et al. (2013). Additional breaching scenarios with intermediate inlet spacing were not considered in this study because it is unlikely that a new inlet will develop at wider and higher sections of Pea Island in the short-term.

The combined action of sea level rise and storms makes Pea Island vulnerable to breaching events in the future. This study presented an overview of how past and potential future breaching scenarios could alter the hydrodynamics of Oregon Inlet and the surroundings of the barrier island. Future work should address morphological modeling of dual-inlet systems, testing the morphological response of Oregon Inlet to breaching scenarios that could include larger/deeper breaches and a sensitivity analysis to inlet spacing. Such morphological simulations should be targeted towards a direct assessment of stability of dual-inlet systems.

\section{REFERENCES}

Birkemeier, W., Dolan, R., Fisher, N., 1984. Evolution of a barrier island: 1930-1980. Shore and Beach, $52,2-12$.

Blanton, B., Madry, S., Galluppi, K., Gamiel, K., Lander, H., Reed, M., Stillwell, L., BlanchardMontgomery, M., 2008. Report for the State of North Carolina floodplain mapping project: coastal flood analysis system. Topographic/bathymetric data.

Booij, N., Ris, R.C., Holthuijsen, L.H., 1999. A third-generation wave model for coastal regions: 1 model description and validation. Journal of Geophysical Research, 104, 7649-7666.

Deltares, 2014a. Delft3D - FLOW. Simulation of multi-dimensional hydrodynamic flows and transport phenomena, including sediments. User Manual. Deltares, Delft, The Netherlands.

Farinha-Fabiao, J. P., Gomez-Rodrigues, M. F., Fortunato, A. B., Quintela de Brito Jabob, J. M., and Francisco-Cravo, A. M., 2016. Water exchanges between a multi-inlet lagoon and the ocean: the role of forcing mechanisms. Ocean Dynamics, 66(2), 173-194.

Fisher, J.J., 1962. Geomorphic expression of former inlets along the Outer Banks of North Carolina. University of North Carolina.

Friedrichs, C. T., Aubrey, D. G., Giese, G. S., and Speer, P. E., 1993. Hydrodynamical modeling of a multiple-inlet estuary/barrier system: insight into tidal inlet formation and stability. Formation and Evolution of Multiple Tidal Inlets, D. G. Aubrey and G. S. Giese, eds., American Geophysical Union, 95-112.

Hayes, M. O., and FitzGerald, D. M., 2013. Origin, evolution, and classification of tidal inlets. Journal of Coastal Research, 6(69), 14-33.

Jarrett, J. T., 1976. Tidal Prism - Inlet Area Relationships. General Investigation of Tidal Inlets (GITI) report 3.

Joyner, B.P., Overton, M.F., Fisher, J.S., 1998. Post-stabilization morphology of Oregon Inlet, NC, in: the 26th International Conference in Coastal Engineering. Copenhagen, Denmark, pp. 31243137.

van de Kreeke, J., 1990. Can multiple tidal inlets be stable? Estuarine, Coastal and Shelft Science Journal, 30, 261-273.

van de Kreeke, J., Brouwer, R. L., Zitman, T. J., and Schuttelaars, H. M., 2008. The effect of a topographic high on the morphological stability of a two-inlet bay system. Coastal Engineering, 55(4), 319-332.

Kurum, O., Overton, M., and Mitasova, H., 2012. Land cover and sediment layers as controls of inlet breaching. In: Proceedings of the 33rd International Conference on Coastal Engineering, Santander, Spain, 1-9. 
Kurum, O., 2013. Improved post-storm model predictions of barrier island response to extreme events by including land cover effects on sediment transport capacity. North Carolina State University.

Leendertse, J. J., 1967. Aspects of a computational model for long- period water-wave propagation. Rand Corporation, Santa Monica, California.

Lesser, G.R., Roelvink, J.A., van Kester, J.A.T.M., Stelling, G.S., 2004. Development and validation of a three-dimensional morphological model. Coastal Engineering, 51, 883-915.

Luettich, R.A., Westerink, J.J., Scheffner, N.W., 1992. ADCIRC: an advanced three-dimensional circulation model for shelves coasts and estuaries, report 1: theory and methodology of ADCIRC2DDI and ADCIRC-3DL. Dredging Research Program Technical Report DRP-92-6. Vicksburg, MS.

Mallinson, D. J., Smith, C. W., Culver, S. J., Riggs, S. R., and Ames, D., 2010. Geological characteristics and spatial distribution of paleo-inlet channels beneath the Outer Banks barrier islands, North Carolina, USA. Estuarine, Coastal and Shelf Science, 88(2), 175-189.

Nichols, C.R., Pietrafesa, L.J., 1997. Oregon Inlet: hydrodynamics, volumetric flux and implications for larval fish transport. Raleigh, NC

Overton, M. F., and Fisher, J. S., 2004. Hurricane Isabel and NC12 hotspots. Shore \& Beach, 72(2), 3035.

Pacheco, A., Ferreira, O., Williams, J. J., Garel, E., Vila-Concejo, A., and Dias, J. A., 2010. Hydrodynamics and equilibrium of a multiple-inlet system. Marine Geology, 274, 32-42.

Roelvink, D., Reniers, A., van Dongeren, A., van Thiel de Vries, J., McCall, R., and Lescinski, J., 2009. Modelling storm impacts on beaches, dunes and barrier islands. Coastal Engineering, 56, 11331152.

Roos, P.C., Schuttelaars, H.M., Brouwer, R.L., 2013. Observations of barrier island length explained using an exploratory morphodynamic model. Geophysical Research Letters, 40, 4338-4343.

Safak, I., Warner, J. C., and List, J. H., 2016. Barrier island breach evolution: Alongshore transport and bay-ocean pressure gradient interactions. Journal of Geophysical Research: Oceans, 121, 8720 8730 .

Salles, P., Voulgaris, G., and Aubrey, D. G., 2005. Contribution of nonlinear mechanisms in the persistence of multiple tidal inlet systems. Estuarine, Coastal and Shelf Science, 65, 475-491.

Sciaudone, E. J., Velasquez-Montoya, L., Smyre, E. A., and Overton, M. F. 2016. Spatial and temporal variability in dune field: Pea Island, North Carolina. Shore \& Beach, 84(2), 49-58.

Stutz, M. L., and Pilkey, O. H., 2011. Open-Ocean barrier islands: global influence of climatic, oceanographic, and depositional settings. Journal of Coastal Research, 27(2), 207-222.

Velasquez, L., Sciaudone, E.J., Mitasova, H., Overton, M.F., 2015. Multi-temporal geospatial analysis of the evolution and closing of pea island breach, NC. In: Proceedings of Coastal Sediments 2015, San Diego, California.

Velasquez-Montoya, L., and Overton, M. F., 2017. Impacts of Seasonal Forcings on the Hydrodynamics of Oregon Inlet, NC. In: Proceedings of Coastal Dynamics, Helsingør, Denmark.

Velasquez-Montoya, L., Sciaudone, E. J., Mitasova, H., and Overton, M. F., 2018. Observation and modeling of the evolution of an ephemeral storm-induced inlet: Pea Island Breach, North Carolina, USA. Continental Shelf Research, 156, 55-69. 